\title{
Tolerância de cultivares de pimentão (Capsicum annuum L.) à salinidade na germinação e crescimento inicial
}

\author{
Tolerance of salinity bell pepper cultivars (Capsicum annuum L.) in germination and initial growth \\ Tolerancia de los cultivares de chile (Capsicum annuum L.) a la salinidad en germinación y \\ crecimiento inicial
}

Recebido: 12/03/2021 | Revisado: 19/03/2021 | Aceito: 23/03/2021 | Publicado: 01/04/2021

\author{
Maiara Pereira Barros \\ ORCID: https://orcid.org/0000-0002-7494-312X \\ Universidade Federal do Ceará, Brasil \\ E-mail: mayarapb20@gmail.com \\ Marcelo de Almeida Guimarães \\ ORCID: https://orcid.org/0000-0002-5329-022X \\ Universidade Federal do Ceará, Brasil \\ E-mail: mguimara@ufc.br \\ Francisco Ronaldo Alves de Oliveira \\ ORCID: https://orcid.org/0000-0003-4752-6387 \\ Instituto Federal do Piaú, Brasil \\ E-mail: ronaldo.oliveira@ifpi.edu.br \\ Haynna Fernandes Abud \\ ORCID: https://orcid.org/0000-0002-3887-1464 \\ Universidade Federal do Ceará, Brasil \\ E-mail: hfabud@gmail.com \\ Charles Lobo Pinheiro \\ ORCID: https://orcid.org/0000-0001-8111-7638 \\ Universidade Federal do Ceará, Brasil \\ E-mail: charlesclp@yahoo.com.br \\ Maria Gina Torres Sena \\ ORCID: https://orcid.org/0000-0002-8406-8728 \\ Universidade Federal do Ceará, Brasil \\ E-mail: ginasenaa@gmail.com \\ Hozano de Souza Lemos Neto \\ ORCID: https://orcid.org/0000-0002-3446-380X \\ Universidade Federal do Ceará, Brasil \\ E-mail: hozanoneto@hotmail.com \\ Carlos Tadeu dos Santos Dias \\ ORCID: https://orcid.org/0000-0003-1015-1761 \\ Universidade Federal do Ceará, Brasil \\ E-mail: ctsdias@ufc.br
}

\begin{abstract}
Resumo
A utilização de cultivares tolerantes à salinidade é uma das estratégias para a produção de alimentos em regiões afetadas pela salinização do solo. Objetivou-se com este estudo avaliar a tolerância de cultivares de pimentão ao estresse salino durante o processo de germinação das sementes e desenvolvimento das plântulas. O experimento foi conduzido em laboratório, adotando-se delineamento inteiramente aleatorizado, em esquema fatorial, com quatro repetições. O primeiro fator foi constituído por duas cultivares de pimentão (Casca Dura Ikeda e Amarelo SF 134); e o segundo, por cinco níveis de salinidade da água $\left(0,0 ; 3,0 ; 6,0 ; 9,0\right.$ e $\left.12,0 \mathrm{dS} \mathrm{m}^{-1}\right)$. Avaliou-se a germinação, primeira contagem de germinação, índice de velocidade de germinação, tempo médio de germinação, comprimento de plântula, massa seca da raiz e parte aérea e índice de tolerância à salinidade. De forma geral, a salinidade da água promoveu efeitos deletérios na germinação e crescimento de plântulas das duas cultivares a partir da CE 6,0 dS m'. A 'Amarelo SF 134' indica apresentar tolerância ao estresse salino no processo germinativo, enquanto a 'Casca Dura Ikeda', na fase de crescimento inicial de plântulas.
\end{abstract}

Palavras-chave: Semiárido; Estresse salino; Solanaceae.

\section{Abstract}

The use of cultivars tolerant to salinity is one of the strategies for food production in regions affected by soil salinization. The objective of this study was to evaluate the tolerance of pepper cultivars to saline stress during the process of seed germination and seedling development. The experiment was conducted in the laboratory, adopting a 
completely randomized design, in a factorial scheme, with four replicates. The first factor consisted of two pepper cultivars (Casca Dura Ikeda and Amarelo SF 134); and the second five levels of water salinity $(0.0 ; 3.0 ; 6.0 ; 9.0$ and $12.0 \mathrm{dS} \mathrm{m} \mathrm{m}^{-1}$ ). Germination, first germination count, germination speed index, average germination time, seedling length, root and shoot dry matter and salinity tolerance index were evaluated. In general, the salinity of the water promoted deleterious effects on the germination and seedling growth of the two cultivars from the EC $6.0 \mathrm{dS} \mathrm{m}^{-1}$. The cultivar 'Amarelo SF 134' indicates greater tolerance to salt stress in the germination process, while 'Casca Dura Ikeda', in the initial seedling growth phase.

Keywords: Semi-arid; Saline stress; Solanaceae.

\section{Resumen}

El uso de cultivares tolerantes a la salinidad es una de las estrategias para la producción de alimentos en las regiones afectadas por la salinización del suelo. El objetivo de este estudio fue evaluar la tolerancia de cultivares de pimiento al estrés salino durante el proceso de germinación de semillas y desarrollo de plántulas. El experimento se realizó en un laboratorio, adoptando un diseño completamente al azar, en un esquema factorial, con cuatro repeticiones. El primer factor consistió en dos cultivares de pimiento (Casca Dura Ikeda y Amarelo SF 134); y el segundo, por cinco niveles de salinidad del agua $\left(0.0 ; 3.0 ; 6.0 ; 9.0\right.$ y $\left.12.0 \mathrm{dS} \mathrm{m} \mathrm{m}^{-1}\right)$. Se evaluó la germinación, primer conteo de germinación, índice de velocidad de germinación, tiempo promedio de germinación, longitud de plántula, materia seca de raíces y brotes e índice de tolerancia a la salinidad. En general, la salinidad del agua promovió efectos deletéreos sobre la germinación y el crecimiento de las plántulas de los dos cultivares de la CE 6.0 dS m². El 'Yellow SF 134' indica tolerancia al estrés salino en el proceso de germinación, mientras que el 'Bark Hard Ikeda', en la fase inicial de crecimiento de la plántula.

Palabras clave: Semiárido; Estrés salino; Solanaceae.

\section{Introdução}

O pimentão (Capsicum annuum L.), da família das solonáceas, é uma das hortaliças mais cultivadas no Brasil, com produção anual próxima de 290.000 toneladas (Souza et al., 2019). Com relevante importância social e econômica no país, os principais estados produtores são Minas Gerais, São Paulo, Rio de Janeiro, Espírito Santo, Ceará e Pernambuco, que juntos somam $87 \%$ da produção nacional (Palmieri et al., 2017).

Em regiões áridas, semiáridas e subúmidas, que representam 45,4\% da superfície terrestre e onde habitam cerca de 2 bilhões de pessoas (Pravalie, 2016), um dos fatores que limitam a produção agrícola é a escassez hídrica em decorrência de frequentes períodos de seca. Diante desse contexto, a utilização de águas salinas na prática da irrigação, muitas vezes, é a única alternativa para viabilizar a produção agrícola. Apesar de ser uma solução para essa problemática, o uso dessas águas na agricultura pode ocasionar a salinização do solo, sobretudo se não houver um manejo adequado da irrigação. Atualmente, estima-se que $20 \%$ de toda terra irrigada no mundo esteja afetada pelo estresse salino (Taiz et al., 2017).

A salinidade do solo constitui um dos principais estresses abióticos e pode causar severas perdas na produção agrícola, principalmente em regiões de climas árido e semiárido (Liang et al., 2018). Entre os efeitos da salinidade nas plantas, pode-se citar: dificuldade de absorção de água em virtude da diminuição do potencial osmótico do solo que, por consequência, diminui o crescimento da parte aérea e reduz a expansão foliar (Taiz et al., 2017); inibição de vários processos biossintéticos em virtude do acúmulo de quantidades elevadas dos íons $\mathrm{Na}^{+}$e $\mathrm{Cl}^{-}$nas folhas, podendo ocorrer também toxidez iônica resultando em danos visíveis principalmente na bordadura das folhas mais velhas (Dias et al., 2016); diminuição e/ou atraso na germinação de sementes e no crescimento de plântulas (Nasri et al., 2015).

De forma geral, esses efeitos variam entre espécies e indivíduos da mesma espécie, intensidade e duração do estresse salino e estádio fenológico (Sá et al., 2017), sendo a fase inicial de crescimento uma das mais sensíveis na maioria das culturas agrícolas (Pinheiro et al., 2018). A cultura do pimentão é classificada como moderadamente sensível à salinidade, havendo redução na produção quando a condutividade elétrica da solução do solo ( $\left.\mathrm{CE}_{\mathrm{s}}\right)$ for maior que 1,5 dS m ${ }^{-1}$ (Mass, 1986). Assim, pesquisas que identifiquem cultivares com tolerância ao estresse salino são cada vez mais necessárias em regiões áridas e semiáridas (Sá et al., 2019). Para Albuquerque et al. (2016), estudos com tolerância de hortaliças à salinidade são uma das alternativas para o convívio com a salinidade nessas regiões. 
Em estudos que buscam identificar genótipos tolerantes à salinidade, os critérios de avaliação podem compreender caracteres morfológicos a exemplo de reduções da matéria seca da parte aérea, radicular e produção de frutos; e fisiológicos como trocas gasosas, atividade de enzimas oxidativas, entre outros (Soares Filho et al., 2016). Além disso, características como germinação, emergência e crescimento de plântulas são também critérios importantes que devem ser considerados para selecionar plantas tolerantes à salinidade (Baath et al., 2017; Sá et al., 2019). Hannachi e Labeke (2018), ao avaliarem respostas morfológicas e fisiológicas de cultivares de berinjela submetidas a estresse salino em diferentes fases, concluíram que a tolerância à salinidade pode ser detectada tanto na fase de germinação, quanto de plântula.

Assim, a partir da hipótese de que existem cultivares de pimentão tolerantes à salinidade, objetivou-se avaliar a tolerância de cultivares de pimentão ao estresse salino durante o processo de germinação das sementes e desenvolvimento das plântulas.

\section{Metodologia}

Este estudo trata-se de uma pesquisa quantitativa e experimental (Gerhardt \& Silveira, 2009), realizada em condições controladas, no Laboratório de Análise de Sementes, pertencente ao Departamento de Fitotecnia da Universidade Federal do Ceará (UFC), Fortaleza, Ceará, entre os meses de abril e maio de 2018.

$\mathrm{O}$ delineamento adotado foi o inteiramente aleatorizado, em esquema fatorial $(2 \times 5)$, com quatro repetições de 50 sementes. O primeiro fator foi constituído por duas cultivares de pimentão (C1: Casca Dura Ikeda e C2: Amarelo SF 134); e o segundo, por cinco níveis salinos da água ( $\mathrm{S} 1=0,0 ; \mathrm{S} 2=3,0 ; \mathrm{S} 3=6,0 ; \mathrm{S} 4=9,0$ e $\mathrm{S} 5=12,0 \mathrm{dS} \mathrm{m}^{-1}$ ), totalizando 40 parcelas experimentais. O nível salino $0,0 \mathrm{dS} \mathrm{m}^{-1}$ (controle) é referente a água destilada, utilizada também nas demais diluições, sendo o ajuste de cada concentração realizado com o auxílio de um condutivímetro de bancada, calibrado para leitura a $25^{\circ} \mathrm{C}$.

A semeadura foi realizada em substrato papel Germitest $₫$ umedecido com as soluções na proporção de 2,5 vezes o peso do papel seco. Em seguida, preparou-se rolos que foram mantidos em câmara de germinação do tipo "Biochemical Oxygen Demand" (BOD), em regime alternado de luz (12 horas sob luz e 12 horas sem) e mantendo a temperatura alternada de 20-30 ${ }^{\circ} \mathrm{C}$ (BRASIL, 2009). Foram avaliadas a germinação (G, \%), primeira contagem de germinação (PCG, \%), índice de velocidade de germinação (IVG), tempo médio de germinação (TMG, dias), comprimento de plântula (CP, cm), massa seca da raiz e parte aérea (MSR e MSPA, mg) e índice de tolerância à salinidade (IT, \%).

A germinação foi avaliada aos quatorze dias após a instalação do teste, considerando-se como germinadas as sementes que apresentaram a raiz primária $>2 \mathrm{~mm}$. A primeira contagem de germinação foi realizada no sétimo dia da instalação do teste, computando-se os percentuais médios de sementes germinadas (BRASIL, 2009). O índice de velocidade de germinação foi mensurado contando-se diariamente o número de sementes que apresentaram raiz primária $>2 \mathrm{~mm}$ até o décimo quarto dia, sendo o resultado obtido com a equação proposta por Maguire (1962). O tempo médio de germinação foi determinado seguindo a metodologia de Labouriau (1983), a partir das contagens diárias até o décimo quarto dia após semeadura.

O comprimento de plântula foi determinado por meio de análise de imagens. Com o auxílio de uma régua graduada para definir a escala da imagem e uma câmera apoiada sobre um sistema adaptado que distava aproximadamente $20 \mathrm{~cm}$ das plântulas, procedeu-se a captura das imagens, que em seguida foram analisadas no software Image ${ }^{\circledR}$. Em seguida, para a obtenção da massa seca da raiz e parte aérea foram selecionadas as plântulas consideradas normais de cada repetição, seccionadas na altura do coleto. Estas foram acondicionadas em sacos de papel previamente identificados colocadas para secar em estufa de circulação forçada de ar, à temperatura de $65^{\circ} \mathrm{C}$ até atingirem uma massa constante. Após esse período, as amostras foram pesadas em balança de precisão $(0,0001 \mathrm{~g})$ e os resultados expressos em mg plântula ${ }^{-1}$. O índice de tolerância à salinidade foi calculado segundo metodologia proposta por Aquino et al. (2007), a partir da MSPA dos tratamentos que foram submetidos aos níveis salinos e o controle $\left(\mathrm{CE}=0,0 \mathrm{dS} \mathrm{m}^{-1}\right)$, como base na seguinte equação: 


$$
\mathrm{IT}(\%)=\frac{\text { MST no tratamento salino }}{\text { MST no tratamento controle }} \times 100
$$

Os dados obtidos foram analisados quanto a existência de pontos discrepantes (outliers) por meio do teste t, homogeneidade da variância pelo teste de Levene e normalidade dos resíduos pelo teste de Shapiro-Wilk. Após verificar que todos os pressupostos foram atendidos, realizou-se a análise de variância pelo teste F. Em seguida, as médias das cultivares foram submetidas à análise de regressão em função dos níveis de salinidade da água, sendo analisadas por meio de equações polinomiais de melhor ajuste, de acordo com a significância dos parâmetros e do coeficiente de determinação. Para todos os testes foi considerado o nível de significância de $5 \%$.

Por fim, a partir do conjunto total de dados, realizou-se a análise da função discriminante canônica buscando-se verificar a existência de separação entre as cultivares considerando os parâmetros de germinação e crescimento de plântulas simultaneamente. Utilizou-se o procedimento PROC CANDISC do SAS/STAT como técnica de redução de dimensão para encontrar combinações lineares das variáveis originais (variáveis canônicas) que discriminam os parâmetros avaliados que mais contribuíram para essa separação (Manly \& Alberto, 2019). Todas as análises foram realizadas utilizando-se o pacote estatístico SAS (SAS Institute Inc., 2012).

\section{Resultados e Discussão}

Os parâmetros analisados apresentaram diferença significativa $(\mathrm{p}<0,01)$ entre tratamentos, com variabilidade dos resultados influenciada pela interação dos fatores 'cultivares' e 'níveis de salinidade', com exceção de germinação (G) e comprimento de plântula (CP), em que se verificou apenas efeito dos fatores principais isoladamente (Tabela 1).

Tabela 1. Resumo da análise de variância para germinação (G), primeira contagem de germinação (PCG), índice de velocidade de germinação (IVG), tempo médio de germinação (TMG), comprimento de plântula (CP), massa seca da raiz e parte aérea (MSR e MSPA) e índice de tolerância à salinidade (IT) de sementes e plântulas de pimentão em função de níveis de salinidade da água.

\begin{tabular}{cccccccccc}
\hline \multirow{2}{*}{ FV } & \multirow{2}{*}{ GL } & \multicolumn{7}{c}{ Quadrados médios } \\
\cline { 3 - 9 } & & G & PCG & IVG & TMG & CP & MSR & MSPA & IT \\
\hline C & 1 & $336,4^{* *}$ & $17388,9^{* *}$ & $267,8^{* *}$ & $61,0^{* *}$ & $0,6^{\text {ns }}$ & $46,2^{* *}$ & $511,2^{* *}$ & $42,4^{\text {ns }}$ \\
S & 4 & $109,1^{* *}$ & $6196,4^{* *}$ & $57,6^{* *}$ & $8,6^{* *}$ & $28,3^{* *}$ & $975,2^{* *}$ & $5314,7^{* *}$ & $13423,5^{* *}$ \\
C x S & 4 & $11,9^{\text {ns }}$ & $966,6^{* *}$ & $42,0^{* *}$ & $2,2^{* *}$ & $0,3^{\text {ns }}$ & $35,4^{* *}$ & $345,9^{* *}$ & $586,8^{* *}$ \\
Erro & 30 & 21,1 & 864,0 & 0,5 & 0,1 & 0,2 & 5,8 & 52,3 & 62,6 \\
\hline CV $(\%)$ & & 5,0 & 8,5 & 8,6 & 4,8 & 11,7 & 13,9 & 16,1 & 11,3 \\
\hline
\end{tabular}

$\mathrm{FV}=$ Fonte de variação; $\mathrm{GL}=$ Grau de liberdade; $\mathrm{C}=$ Cultivar; $\mathrm{S}=$ Salinidade $; \mathrm{C}$ x $\mathrm{S}=$ Interação entre cultivar e salinidade; $\mathrm{CV}=$ Coeficiente de variação; $* * \mathrm{e}^{*}=$ significativo pelo teste $\mathrm{F}$ a 1 e $5 \%$, respectivamente; ${ }^{\text {ns }}=$ não significativo pelo teste $\mathrm{F}$ a $5 \%$.

Fonte: Autores.

O efeito isolado da salinidade para a $\mathrm{G}$ foi ajustado a modelo quadrático (Figura 1A). As duas cultivares apresentaram boa performance quanto a este parâmetro, no entanto, ocorreu decréscimo a partir da CE 6,0 dS m'. A 'Amarelo SF 134' apresentou média superior à 'Casca Dura Ikeda', com 94,2 e 88,4\% de sementes germinadas, respectivamente. Isso demonstra que essa cultivar se destaca em relação a 'Casca Dura Ikeda', provavelmente por possuir mecanismos mais aprimorados que permitem a maior germinação, mesmo diante da diminuição progressiva do potencial osmótico da água.

A primeira contagem de germinação (PCG) e índice de velocidade de germinação (IVG) foram ajustados a modelos quadráticos em função dos níveis de salinidade da água (Figuras 1B e 1C). A cultivar 'Amarelo SF 134' apresentou maiores 
valores de PCG em todos os níveis de $\mathrm{NaCl}$, com máxima de 92,5\% na salinidade de 2,2 $\mathrm{dS} \mathrm{m}^{-1}$, sendo que para a 'Casca Dura Ikeda’ a máxima germinação na primeira contagem foi 58,3\% com a salinidade da água de 4,4 dS m ${ }^{-1}$ (Figura 1B). O índice de velocidade de germinação (IVG) foi ajustado a modelos quadráticos para as duas cultivares (Figura 1C). A cultivar 'Amarelo SF 134' apresentou maiores valores em todos os níveis salinos, sendo o mínimo de 7,4 no nível salino de $10,2 \mathrm{dS} \mathrm{m}^{-1}$. Já a 'Casca Dura Ikeda', teve o IVG máximo de 6,8 na salinidade de 4,1 dS m-1.

Figura 1. Desempenho germinativo de sementes de cultivares de pimentão (C1: Casca Dura Ikeda e C2: Amarelo SF 134) submetidas a níveis de salinidade da água. A: germinação $(\mathrm{G})$; B: primeira contagem de germinação (PCG); C: índice de velocidade de germinação (IVG); D: tempo médio de germinação (TMG).
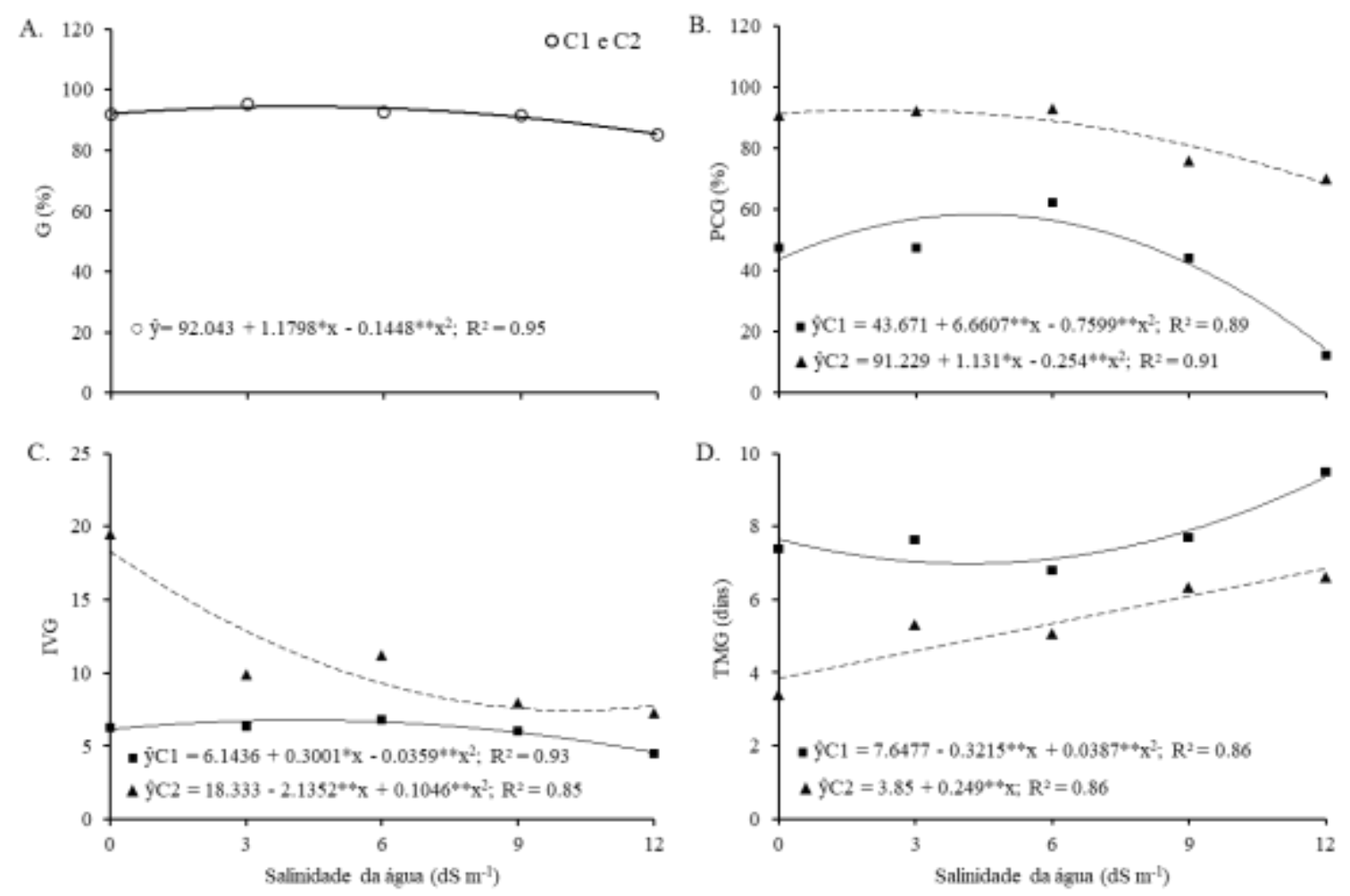

Fonte: Autores.

Para tempo médio de germinação (TMG), ajustou-se modelo quadrático para 'Casca Dura Ikeda' e linear para 'Amarelo SF 134' (Figura 1D). As duas cultivares tiveram aumento no TMG com o incremento na salinidade, no entanto, a cultivar 'Casca Dura Ikeda' foi mais afetada, apresentando maiores valores em todos os níveis salinos. Isso ocorre porque o aumento da concentração salina ocasiona maior limitação na absorção de água pelas sementes e, consequentemente, redução na velocidade da germinação, resultando em maior tempo necessário para as sementes germinarem (Lemos Neto et al., 2018). Pode haver também efeito fitotóxico do $\mathrm{NaCl}$ sobre o embrião das sementes, dificultando a cinética de absorção da água (Bewley et al., 2013).

Para o comprimento de plântulas (CP), houve ajuste de modelo linear para o efeito isolado da salinidade, em que se verifica um decréscimo de 0,39 $\mathrm{cm}$ para o aumento de $1,0 \mathrm{dS} \mathrm{m}^{-1}$ na CE da água (Figura 2A). De acordo com Taiz et al. (2017), a redução do potencial osmótico do meio causado pelo aumento da concentração salina provoca a desidratação e redução da expansão celular, diminuindo assim o crescimento. Decréscimo linear em altura de plântulas causado pelo aumento da salinidade da água também foi relatado por Sá et al. (2017), Baath et al. (2017) e Lemos Neto et al. (2018), em cultivares de 
pimentão, pimenta e alface, respectivamente.

Figura 2. Crescimento de cultivares de pimentão (C1: Casca Dura Ikeda e C2: Amarelo SF 134) submetidas a níveis de salinidade da água. A: comprimento de plântula (CP); B: massa seca de raízes (MSR); C: massa seca da parte aérea (MSPA); D: índice de tolerância a salinidade (IT).
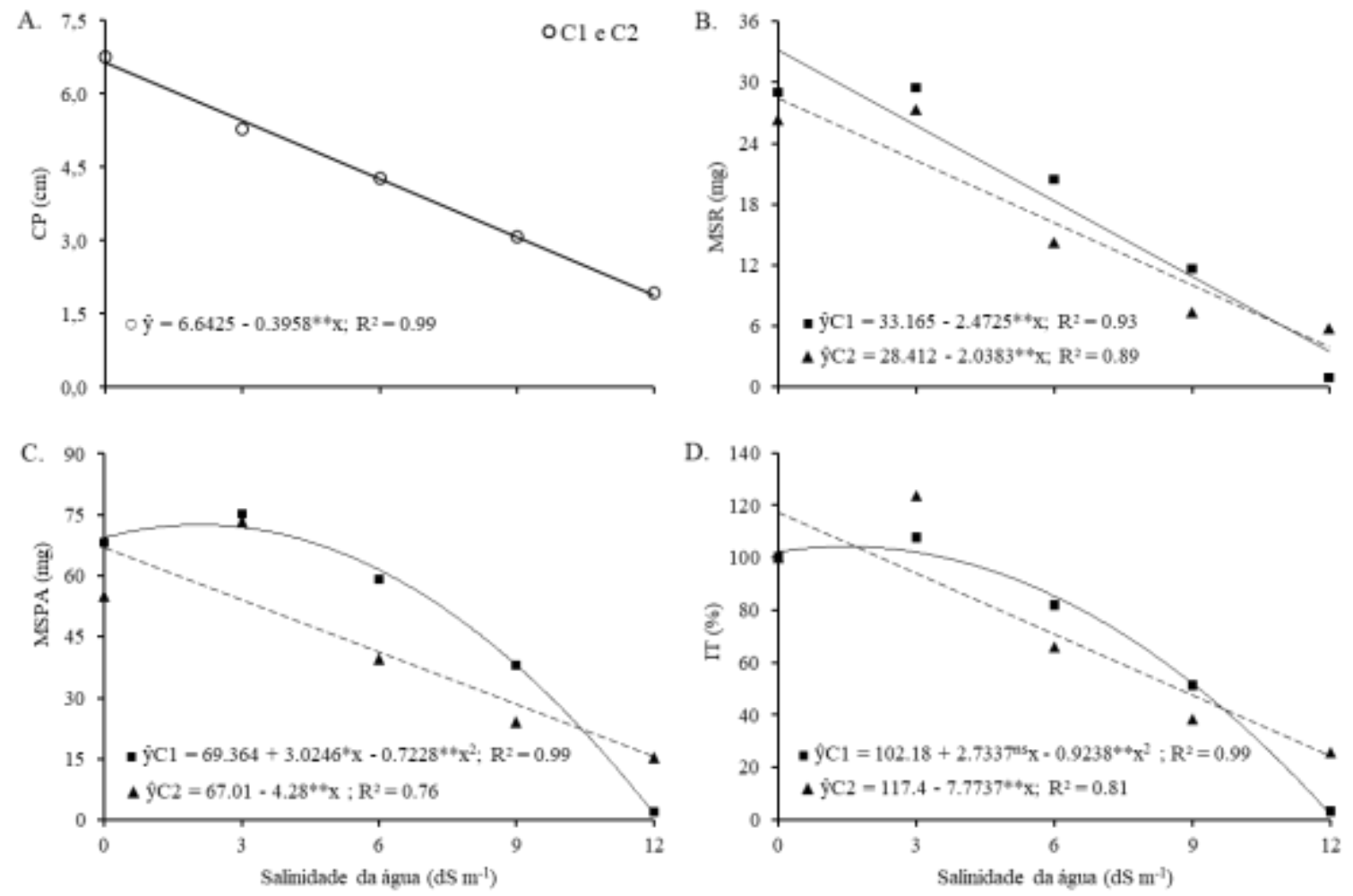

Fonte: Autores.

A massa seca das raízes (MSR) foi ajustada a modelo linear decrescente em função dos níveis de salinidade para as duas cultivares (Figura 2B), com a 'Casca Dura Ikeda' mostrando-se superior a 'Amarelo SF 134' até o nível salino de 9,0 dS $\mathrm{m}^{-1}$. A redução na MSR para o acréscimo de $1,0 \mathrm{dS} \mathrm{m}^{-1}$ na solução, foi de 2,5 e 2,0 mg para 'Casca Dura Ikeda' e 'Amarelo SF 134', respectivamente. Para massa seca da parte aérea (MSPA), também houve efeito negativo da salinidade, sendo ajustado modelo quadrático para 'Casca Dura Ikeda' e linear para 'Amarelo SF 134' (Figuras 2C). A cultivar 'Casca Dura Ikeda' produziu mais biomassa na parte aérea, sendo a máxima produção $(72,5 \mathrm{mg})$ no nível salino de $2,1 \mathrm{dS} \mathrm{m}^{-1}$. Já o índice de tolerância à salinidade (IT), que retrata o percentual de matéria seca total nos tratamentos salinos em relação ao controle, ajustou-se a modelo quadrático para 'Casca Dura Ikeda' e linear para 'Amarelo SF 134' (Figura 2D). Observa-se que para 'Casca Dura Ikeda' o IT máximo (97,0\%) ocorreu na CE de 1,5 dS m-1, já para 'Amarelo SF 134', verifica-se decréscimo de 7,7\% para o incremento de $1,0 \mathrm{dS} \mathrm{m}^{-1}$ na água. Ressalta-se que no último nível salino (12,0 dS m $\left.\mathrm{m}^{-1}\right)$, a 'Amarelo SF 134' apresenta IT de $25,9 \%$ e a 'Casca Dura Ikeda' de 2,9\%.

A redução na biomassa de plântulas em decorrência do aumento da concentração salina na água também é relatada para a cultura do pimentão por Sá et al. (2017), como também para outras espécies de hortaliças como alface (Lemos Neto et al., 2018), berinjela (Hannachi \& Labeke, 2018) e pimenta (Sá et al., 2019). Além do efeito osmótico já citado, a diminuição da massa seca pode ser causada pela alta concentração de íons como o cloreto e o sódio que afetam os mecanismos de hidrólise e mobilização de reservas das plântulas (Pedó et al., 2014). Além disso, afeta diretamente as respostas fisiológicas das sementes, 
bem como causa distúrbios hormonais em plântulas, reduzindo assim o crescimento inicial (Albuquerque et al., 2016).

A análise discriminante demonstra que as duas primeiras funções discriminantes ou variáveis canônicas (CAN1 e CAN2) explicaram 79,1\% da variância total dos dados, sendo que 50,9\% é explicada na CAN1, e 28,2\% na CAN2 (Tabela 2).

Tabela 2. Coeficientes canônicos brutos e variação total explicada pelas duas primeiras variáveis canônicas (CAN1 e CAN2), considerando parâmetros de germinação e crescimento de plântulas de cultivares de pimentão submetidas a níveis de salinidade da água.

\begin{tabular}{lcc}
\hline Variável & CAN1 & CAN2 \\
\hline Germinação (G) & $-0,02$ & $-0,18$ \\
Primeira contagem de germinação (PCG) & $-0,02$ & 0,30 \\
Índice de velocidade de germinação (IVG) & 0,84 & 0,62 \\
Tempo médio de germinação (TMG) & $-1,73$ & 2,43 \\
Comprimento de plântulas (CP) & 0,31 & $-1,70$ \\
Matéria seca da raiz (MSR) & $-0,22$ & $-0,50$ \\
Matéria seca da parte aérea (MSPA) & 0,02 & 0,20 \\
Índice de tolerância (IT) & 0,10 & -0.05 \\
\hline Variância explicada (\%) & 50,9 & 28,2 \\
Variância acumulada (\%) & 50,9 & 79,1 \\
\hline
\end{tabular}

Fonte: Autores.

A partir dos coeficientes canônicos brutos (Tabela 2), CAN1 e CAN2 podem ser representadas por: CAN1 $=$ [0,02(G) - 0,02(PCG) + 0,84(IVG) - 1,73(TMG) + 0,31(CP) - 0,22(MSR) + 0,02(MSPA) + 0,10(IT)]; CAN2 = [- 1,18(G) + $0,29(\mathrm{PCG})+0,62(\mathrm{IVG})+2,43(\mathrm{TMG})-1,70(\mathrm{CP})-0,50(\mathrm{MSR})+0,20(\mathrm{MSPA})-0,05(\mathrm{IT})]$. Os maiores valores em módulo contidos em CAN1 e CAN2 representam os parâmetros que mais contribuíram para a separação dos tratamentos, uma vez que estas variáveis canônicas refletem importante percentual da variação total dos dados (Manly \& Alberto, 2019).

A separação entre as cultivares 'Casca Dura Ikeda (C1)' e 'Amarelo SF 134 (C2)' fica evidente na Figura 3. Considerando os maiores coeficientes canônicos brutos em módulo da primeira varável canônica (CAN1), maior contribuição para separação dos tratamentos é observado para IVG e TMG. Conforme foi verificado nas análises de regressão, a cultivar 'Amarelo SF 134' foi a que apresentou melhor desempenho para estes parâmetros. Esses resultados sugerem que a cultivar 'Amarelo SF 134' apresenta características de tolerância ao estresse salino no processo germinativo, podendo ser um genótipo útil em programas de melhoramento que busquem variedades de pimentão tolerantes à salinidade.

Nesse caso, diante da restrição osmótica causada pela concentração de $\mathrm{NaCl}$, as sementes possivelmente intensificaram a atividade metabólica para promover um ajustamento osmótico que permitiu a absorção satisfatória de água e possibilitou a germinação mesmo em condições de estresse salino (Sá et al., 2019). 
Figura 3. Dispersão dos tratamentos considerando parâmetros de germinação e crescimento de plântulas de cultivares de pimentão (C1: Casca Dura Ikeda e C2: Amarelo SF 134) submetidas a níveis de salinidade da água e as variáveis canônicas 1 e 2 (CAN1 e CAN2).

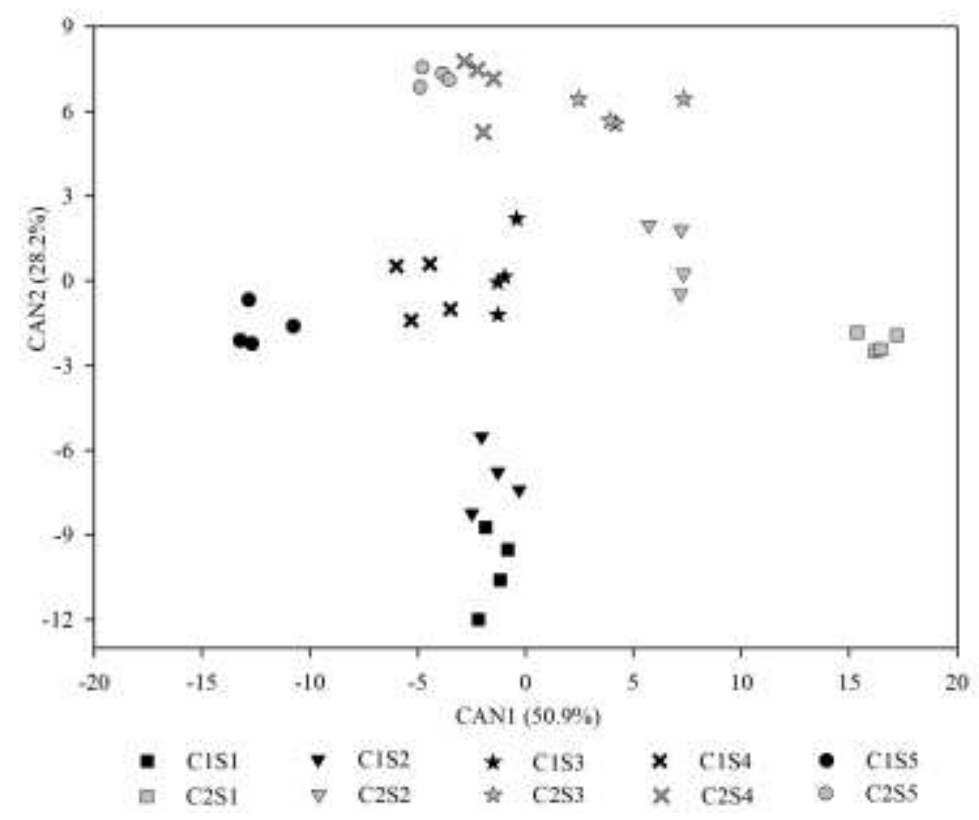

Fonte: Autores.

Em relação a CAN2, os parâmetros que mais contribuíram foram IVG, TMG CP e MSR. Recorrendo novamente ao que foi verificado nas análises de regressão, a cultivar 'Amarelo SF 134' apresentou maiores valores para IVG, TMG e CP, enquanto a 'Casca Dura Ikeda', para MSR e demais parâmetros de crescimento de plântulas. Os maiores valores de MSR podem indicar uma alteração morfológica da 'Casca Dura Ikeda' em resposta ao estresse salino (plasticidade fenotípica). Segundo Taiz et al. (2017), essa plasticidade pode resultar em mudanças anatômicas adaptativas que capacitam as plantas a evitar alguns dos efeitos prejudiciais do estresse abiótico. Dessa forma, o maior crescimento das raízes, aliado a outros mecanismos, pode ter favorecido o aumento da capacidade de absorção de água e, consequentemente, contribuído para um melhor desempenho dessa cultivar nos demais parâmetros de crescimento inicial de plântulas.

\section{Conclusão}

A salinidade da água promoveu efeitos deletérios na germinação e crescimento de plântulas das cultivares de forma acentuada a partir da CE 6,0 $\mathrm{dS} \mathrm{m}^{-1}$.

A cultivar 'Amarelo SF 134' indica apresentar maior tolerância ao estresse salino no processo germinativo, enquanto a 'Casca Dura Ikeda', na fase de crescimento inicial de plântulas.

Estudos que avaliem a emergência e o desenvolvimento dessas cultivares irrigadas com água salina em condições de campo são necessários para que assim seja confirmada a tolerância desses genótipos à salinidade.

\section{Agradecimentos}

Os autores agradecem à Universidade Federal do Ceará (UFC); à equipe do Laboratório de Análise de Sementes da UFC; e ao Núcleo de Estudos em Olericultura do Nordeste (NEON), pelo suporte e apoio técnico na realização deste estudo. 
Ao Conselho Nacional de Desenvolvimento Científico e Tecnológico (CNPq) pela concessão de bolsas aos envolvidos no trabalho.

\section{Referências}

Albuquerque, J. R. T., Sá, F. V. S., Oliveira, F. A., Paiva, E. P., Araújo, E. B. G., \& Souto, L. S. (2016). Crescimento inicial e tolerância de cultivares de pepino sob estresse salino. Revista Brasileira de Agricultura Irrigada, 10 (2), 486-495. 10.7127/RBAI.V10N200355.

Aquino, A. J. S., Lacerda, C. F., Bezerra, M. A., Gomes Filho, E., \& Costa, R. N. T. (2007). Crescimento, partição de matéria seca e retenção de Na ${ }^{+}, \mathrm{K}^{+}$e Cl em dois genótipos de sorgo irrigados com águas salinas. Revista Brasileira de Ciência do Solo, 31 (5), 961-971. https://doi.org/10.1590/S010006832007000500013

Baath, G. S., Shukla, M. K., Bosland, P. W., Steiner, R. L., \& Walker, S. J. (2017). Irrigation water salinity influences at various growth stages of Capsicum annuum. Agricultural Water Management, 179 (1), 246-253. https://doi.org/10.1016/j.agwat.2016.05.028.

Bewley, J. D., Bradford, K. J., Hilhorst, H. W. M., \& Nonogaki, H. (2013). Seeds: physiology of development, germination and dormancy. (3rd). Springer.

Dias, N. S., Blanco, F. F., Souza, E. R., Ferreira, J. F. S., Sousa Neto, O. N., \& Queiroz, I. S. R. (2016). Efeitos dos sais na planta e tolerância das culturas à salinidade. In: Gheyi, H. R., Dias, N. S., Lacerda, C. F., \& Gomes Filho, E. (Ed.) Manejo da salinidade na agricultura: estudos básicos e aplicados. (2 ed). INCTSal.

Hannachi, S., \& Labeke, M. C. V. (2018). Salt stress affects germination, seedling growth and physiological responses differentially in eggplant cultivars (Solanum melongena L.). Scientia Horticulturae, 228, 56-65. https://doi.org/10.1016/j.scienta.2017.10.002.

Labouriau, L. G. (1983). A germinação das sementes. OEA.

Lemos Neto, H. S., Guimarães, M. A., Sampaio, I. M. G., Hendges, A. R. A. A., Oliveira, A. B., \& Medeiros Filho, S. (2018). Silicon (Si) reduces the effects of salt stress on germination and initial growth of lettuce (Lactuca sativa L.). Australian Journal of Crop Science, 12 (09), 1410-1418. 10.21475/ajcs.18.12.09.PNE1074.

Liang, W., Ma, X., Wan, E., \& Liu, L. (2018). Plant salt-tolerance mechanism: A review. Biochemical and Biophysical Research Communications, 495, 286291. https://doi.org/10.1016/j.bbrc.2017.11.043.

Manly, B. F. J., \& Alberto, J. A. N. (2019). Métodos estatísticos multivariados: uma introdução. (4a ed). Bookman.

Maguire, J. D. (1962). Speed of germination-aid in selection and evaluation for seedling emergence and vigor. Crop Science, 2 (1), 176-177. https://doi.org/10.2135/cropsci1962.0011183X000200020033x.

Maas, E. V. (1986). Salt tolerance of plants. Applied Agriculture Research, 1, 12-26.

Ministério da Agricultura, Pecuária e Abastecimento. (2009). Regras para Análisesementes. Mapa/ACS.

Nasri, N., Saïdi, I., Kaddour, R., \& Lachaâl, M. (2015). Effect of salinity on germination, seedling growth and acid phosphatase activity in lettuce. American Journal of Plant Sciences, 6 (1), 57-63. http://dx.doi.org/10.4236/ajps.2015.61007.

Negrão, S., Schmöckel, S. M., \& Tester, M. (2017). Evaluating physiological responses of plants to salinity stress. Annals of Botany, 119 (1), 1-11. https://doi.org/10.1093/aob/mcw191.

Palmieri, F. G., Rodrigues, G. G., \& Marcomini, L. R. S. (2017). Pequenos mercados, grandes oportunidades: boas opções para diversificar a produção. Hortifruti Brasil, 171, 8-14.

Pedó, T., Aisenberg, G. R., Aumonde, T. Z., \& Villela, F. A. (2014). Desempenho fisiológico de sementes e plântulas de genótipos de cucurbitaceae e solanaceae em ambiente salino. Revista Tecnologia \& Ciência Agropecuária, 8 (2), 1-7.

Pinheiro, C., Ribeiro, I. C., Reisinger, V., Planchon, S., Veloso, M. M., Renaut, J., Eichacker, L., \& Ricardo, C. P. (2018). Salinity effect on germination, seedling growth and cotyledon membrane complexes of a Portuguese salt marsh wild beet ecotype. Theoretical and Experimental Plant Physiology, 30 (2), 113-127. https://doi.org/10.1007/s40626-018-0107-4.

Pravalie, R. (2016). Drylands extent and environmental issues: A global approach. Earth-Science Reviews, 161, 259-278. https://doi.org/10.1016/j.earscirev.2016.08.003.

Sá, F. V. S., Souto, L. S., Paiva, E. P., Araújo, E. B. G., Oliveira, F. A., Mesquita, E. F., Ferreira Neto, M., \& Dantas, J. S. (2017). Initial development and tolerance of bell pepper (Capsicum annuum) cultivars under salt stress. Journal of Agricultural Science, 9 (11), 181-189. https://doi.org/10.5539/jas.v9n11p181.

Sá, F. V. S., Souto, L. S., Paiva, E. P., Torres, S. B., \& Oliveira, F. A. (2019). Initial development and tolerance of pepper species to salinity stress. Revista Caatinga, 32 (3), 826-833. https://doi.org/10.1590/1983-21252019v32n327rc.

SAS. SAS/STAT® 9.3 User's Guide. (2012). SAS Institute Inc., Cary.

Gerhardt, T. E., \& Silveira, D. T. (2009). Métodos de pesquisa. Editora da UFRGS. 
Research, Society and Development, v. 10, n. 4, e9110413851, 2021

(CC BY 4.0) | ISSN 2525-3409 | DOI: http://dx.doi.org/10.33448/rsd-v10i4.13851

Soares Filho, W. S., Gheyi, H. R., Brito, M. E. B., Nobre, R. G., Fernandes, P. D., \& Miranda, R. S. (2016). Melhoramento genético e seleção de cultivares tolerantes à salinidade. In: Gheyi, H. R., Dias, N. S., Lacerda, C. F., \& Gomes Filho, E. (Ed.) Manejo da salinidade na agricultura: estudos básicos e aplicados. (2a ed). INCTSal.

Souza, I. L., Tomazella, V. B., Santos, A. J. N., Moraes, T., \& Silveira, L. C. P. (2019). Parasitoids diversity in organic Sweet Pepper (Capsicum annuum) associated with Basil (Ocimum basilicum) and Marigold (Tagetes erecta). Brazilian Journal of Biology, 79 (4), 603-611. https://doi.org/10.1590/15196984.185417.

Taiz, L., Zeiger, E., Moller, I. M., \& Murphy, A. (2017). Fisiologia e Desenvolvimento Vegetal. (6a ed). Artmed. 